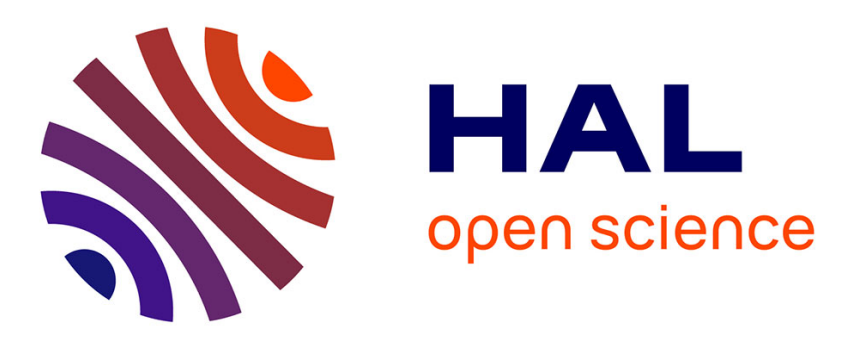

\title{
Tailoring the morphology of photowritten buried waveguides by helical trajectory in As2S3 glass
}

Ophélie Caulier, Pascal Masselin, Eugène Bychkov, David Le Coq

\section{To cite this version:}

Ophélie Caulier, Pascal Masselin, Eugène Bychkov, David Le Coq. Tailoring the morphology of photowritten buried waveguides by helical trajectory in As2S3 glass. Optics and Laser Technology, 2016, 78, Part B, pp.56-61. 10.1016/j.optlastec.2015.09.032 . hal-01220883

HAL Id: hal-01220883

https://hal-univ-rennes1.archives-ouvertes.fr/hal-01220883

Submitted on 26 Nov 2015

HAL is a multi-disciplinary open access archive for the deposit and dissemination of scientific research documents, whether they are published or not. The documents may come from teaching and research institutions in France or abroad, or from public or private research centers.
L'archive ouverte pluridisciplinaire HAL, est destinée au dépôt et à la diffusion de documents scientifiques de niveau recherche, publiés ou non, émanant des établissements d'enseignement et de recherche français ou étrangers, des laboratoires publics ou privés. 


\title{
Tailoring the morphology of photowritten buried waveguides by helical trajectory in $\mathrm{As}_{2} \mathrm{~S}_{3}$ glass
}

\author{
Ophélie Caulier ${ }^{1}$, Pascal Masselin ${ }^{1}$, Eugène Bychkov ${ }^{1}$, David Le Coq ${ }^{2, *}$ \\ ${ }^{1}$ Laboratoire de Physico Chimie de l'Atmosphère, EA 4493 Université du Littoral Côte d'Opale, 59140 \\ Dunkerque, France \\ ${ }^{2}$ Institut des Sciences Chimiques de Rennes, Eq. Verres et Céramiques, UMR CNRS 6226, Université de Rennes \\ 1, 35042 Rennes Cedex, France \\ * Corresponding author: david.lecoq@univ-rennes1.fr \\ Phone/Fax : +33 (0)223235423/5611
}

\begin{abstract}
This paper deals with the control of the refractive index variation $(\Delta \mathrm{n})$ profile induced by femtosecond laser irradiation in the bulk of $\mathrm{As}_{2} \mathrm{~S}_{3}$ glass. The writing technique consists of an original laser inscription based on a helical translation of the sample parallel to the laser beam. Instead of inscribing the core of the waveguide as usually performed, the laser beam is used to induce a negative refractive index variation and consequently to write the cladding of the waveguide. However, it should be noticed that the matter displacement resulting from local heating leads to a densification at the center of the helix, which induces a positive $\Delta \mathrm{n}$ relatively to the matrix. Therefore, the structure of $\Delta \mathrm{n}$ is complex, being composed of a positive core surrounded by a negative cladding. The influence of different parameters on the $\Delta \mathrm{n}$ profiles such as the sample translation velocity, the pitch and the radius of the helical displacement, and the pulse energy are analyzed. This study demonstrates that both $\Delta \mathrm{n}$ and its diameter can be varied in a wide range of values and picked independently, allowing the design of single or multimode buried infrared waveguide.
\end{abstract}

Keywords: Chalcogenide glasses - Femtosecond laser - Laser materials processing Photoinscription - Infrared waveguide

\section{Introduction}

Focused ultrashort-pulsed laser pulses induce refractive index modifications in glass. This constitutes a real opportunity to generate three-dimensional optical components $[1,2,3]$. The advantages of this technique are numerous. Among them, the possibility to inscribe a waveguiding structure in a single step, without chemical process, is of particular interest because of its rapidity. Moreover, the laser writing allows the inscription of complex structures. For example, the realization of Mach-Zender interferometers [4] or of double waveguide couplers [5] have already been demonstrated. Due to their specific optical [6,7] or electrical properties $[8,9]$ chalcogenide glasses $(\mathrm{ChG})$ are an integral part of a scientific research domain [10], especially if the spectral region of interest is the infrared range.

Complementary common characteristics of ChG are their high optical nonlinearities [11] and their high photo-sensitivity [12] which make the inscription of refractive index variation $(\Delta \mathrm{n})$ easy. Consequently, they have been the subject of many investigations in the laser photoinscription field $[13,14,15,16,17,18]$.

The understanding of the fundamental and physical processes induced by the laser pulse is the basis of controlling the refractive index changes and consequently of realizing new integrated 
photonic devices. According to the composition of the chalcogenide glasses, many phenomena can occur during the irradiation. In the case of $\mathrm{As}_{2} \mathrm{~S}_{3}$, at high repetition rate of femtosecond pulsed laser, the involved thermal effects have been shown to produce either low positive or negative $\Delta \mathrm{n}$ amplitude depending of the pulse energy when longitudinal writing geometry is used [19]. However, an original writing technique based on a helical translation of the sample throughout the focal point of the laser beam has been recently successfully demonstrated to obtain large positive $\Delta \mathrm{n}$ allowing infrared waveguiding [20]. This very promising technique opens a new route to the fabrication of buried infrared waveguides. The homogeneity of the inscriptions has also been achieved over more than $25 \mathrm{~mm}$ by solving the drawbacks due to the longitudinal trajectory [20].

In this paper, an overview of different parameters involved in the helical writing process, which directly influence the morphology of $\Delta \mathrm{n}$ in the glass $\mathrm{As}_{2} \mathrm{~S}_{3}$, is given. We highlight the potential of this writing process to inscribe a buried waveguide with large ranges of both $\Delta \mathrm{n}$ amplitude and diameter considered independently.

\section{Experimental section}

\section{II.1. Sample preparation}

$\mathrm{As}_{2} \mathrm{~S}_{3}$ glass sample was synthesized from high purity As $(5 \mathrm{~N})$ and $\mathrm{S}(4 \mathrm{~N})$. These elements were separately distilled before weighting in stoichiometric proportions in a glove box under Ar atmosphere and introduced together in a silica set-up before evacuation $\left(10^{-5} \mathrm{~Pa}\right)$. A final distillation was performed down to a melting ampoule which was isolated by sealing and placed in a rocking furnace for 24 hours at $750^{\circ} \mathrm{C}$. The quench was operated in water at room temperature. The sample was finally annealed at the glass transition temperature $T_{g}$ for 4 hours before being slowly cooled down to room temperature in order to relax internal stress. The rod of $10 \mathrm{~mm}$ diameter was then cut and polished down to optical quality into a parallelepiped of $7 \times 7 \times 25 \mathrm{~mm}^{3}$.

\section{II.2. Principle of the helical inscription}

A Ti:sapphire ultrafast laser (Coherent Mira) was employed at a high repetition rate of 76 $\mathrm{MHz}$ and a nominal output pulse duration of $200 \mathrm{fs}$ with a central wavelength of $800 \mathrm{~nm}$. The energy per pulse was adjusted by using two crossed polarizers, the latter one being in a fixed position while the first one was rotated for adjustment. The beam was focused into the sample with a $f=50 \mathrm{~mm}$ lens $(\mathrm{NA}=0.03)$ and the $1 / \mathrm{e}^{2}$ intensity radius at the focal point was estimated to be $20 \mu \mathrm{m}$ in air. The sample was fixed on three translation stages: (i) two Newport XMS-160, for circular movement in the (x,y) plane, and (ii) one Newport GTS-150, for linear translation along the beam propagation axis $(\mathrm{z})$. The rotation velocity was fixed to $\omega$ $=75 \mathrm{rad} / \mathrm{s}$ meaning that a complete circle in the $(\mathrm{x}, \mathrm{y})$ plane was done in $2 \pi / \omega \approx 0.084 \mathrm{~s}$. A scheme of the helical writing is depicted in Fig. 1(a), and an outline the corresponding $\Delta \mathrm{n}$ modification is given in Fig. 1(b) considering that the experimental conditions lead to an inscription with a negative $\Delta \mathrm{n}$. 


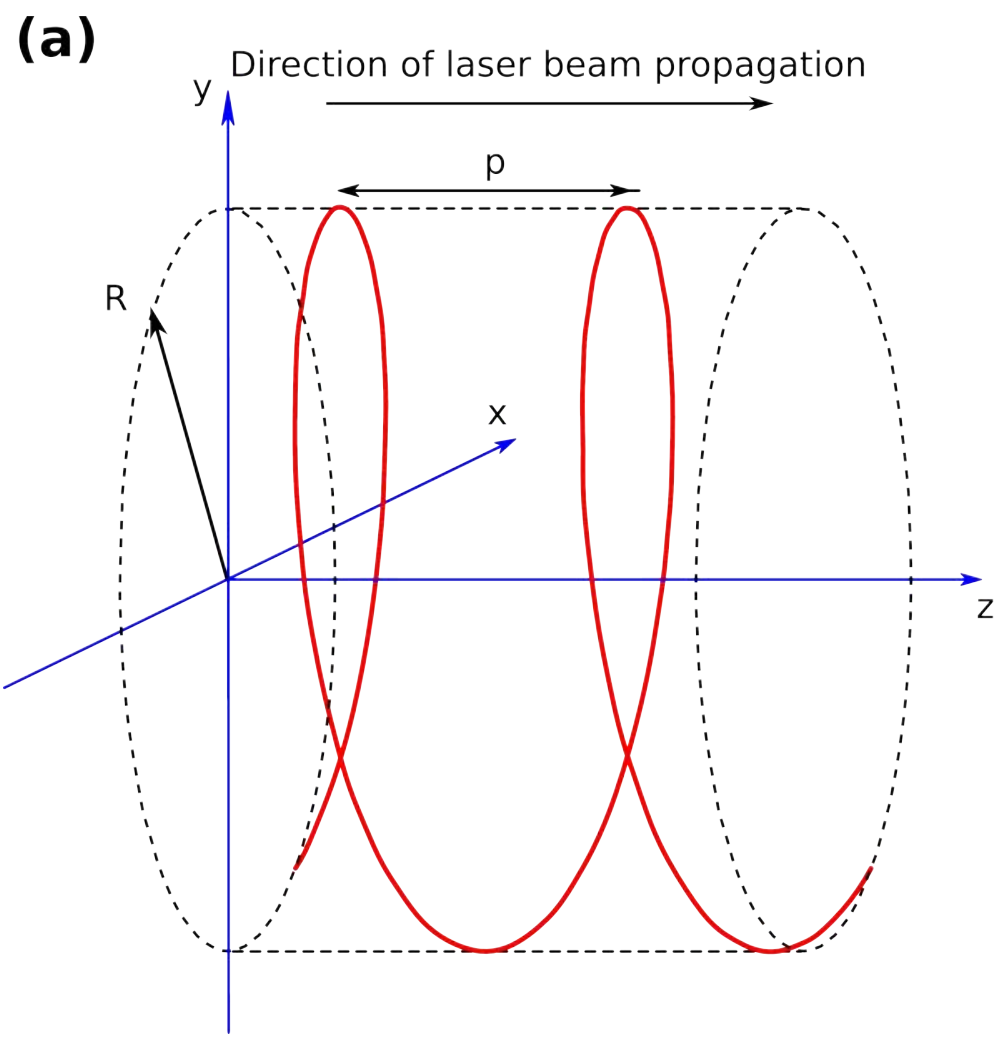

(b)

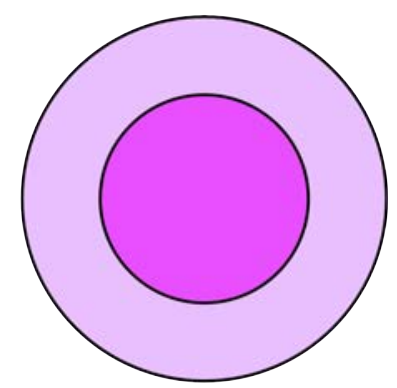

Figure 1: (a) Scheme of the helical writing in the bulk of the glass $\mathrm{As}_{2} \mathrm{~S}_{3} . R$ is the radius of the helix and $p$ is the helix pitch. (b) (x,y) plane image of the $\Delta$ n modification after the helical writing.

\section{II.3. $\Delta \mathrm{n}$ profile reconstruction}

The first step in the reconstruction of the $\Delta n$ profile is done by quantitative phase imaging [21] according to the procedure described in Ref [22]. All the images are recorded with a standard microscope equipped with a Hammamatsu OrcaR ${ }^{2}$ camera. As the phase profile is axially symmetric, an Abel inversion, following a Nestor-Olsen algorithm can be applied to the phase image to obtain spatially resolved $\Delta n(r)[23,24]$ ( $r$ is the transverse direction). All measurements were carried out by using a wavelength around $630 \mathrm{~nm}$.

The onset of the Fig. 2(a) is a three-dimensional transverse reconstruction of the $\Delta \mathrm{n}$ profile. The helical writing technique allows obtaining a perfect circular structure in term of $\Delta \mathrm{n}$ modification. Fig. 2(a) exhibits a typical longitudinal $\Delta \mathrm{n}$ reconstruction. In this example, the power $P$, the helix radius $R$, the helix pitch $p$, and the z-translation velocity were $50 \mathrm{~mW}, 9$ $\mu \mathrm{m}, 25 \mu \mathrm{m}$, and $1000 \mu \mathrm{m} / \mathrm{s}$, respectively. The longitudinal structure presents a positive $\Delta \mathrm{n}$ at the center of the modified $\Delta \mathrm{n}$ area surrounded by a negative $\Delta \mathrm{n}$ ring corresponding to the irradiated zone part. The Fig. 2(b) shows from top to bottom, a photograph of the obtained waveguide, the phase image recorded according to the procedure describes above, and the corresponding $\Delta \mathrm{n}$. This last image emphasizes the homogeneity of the inscription. 
(a)

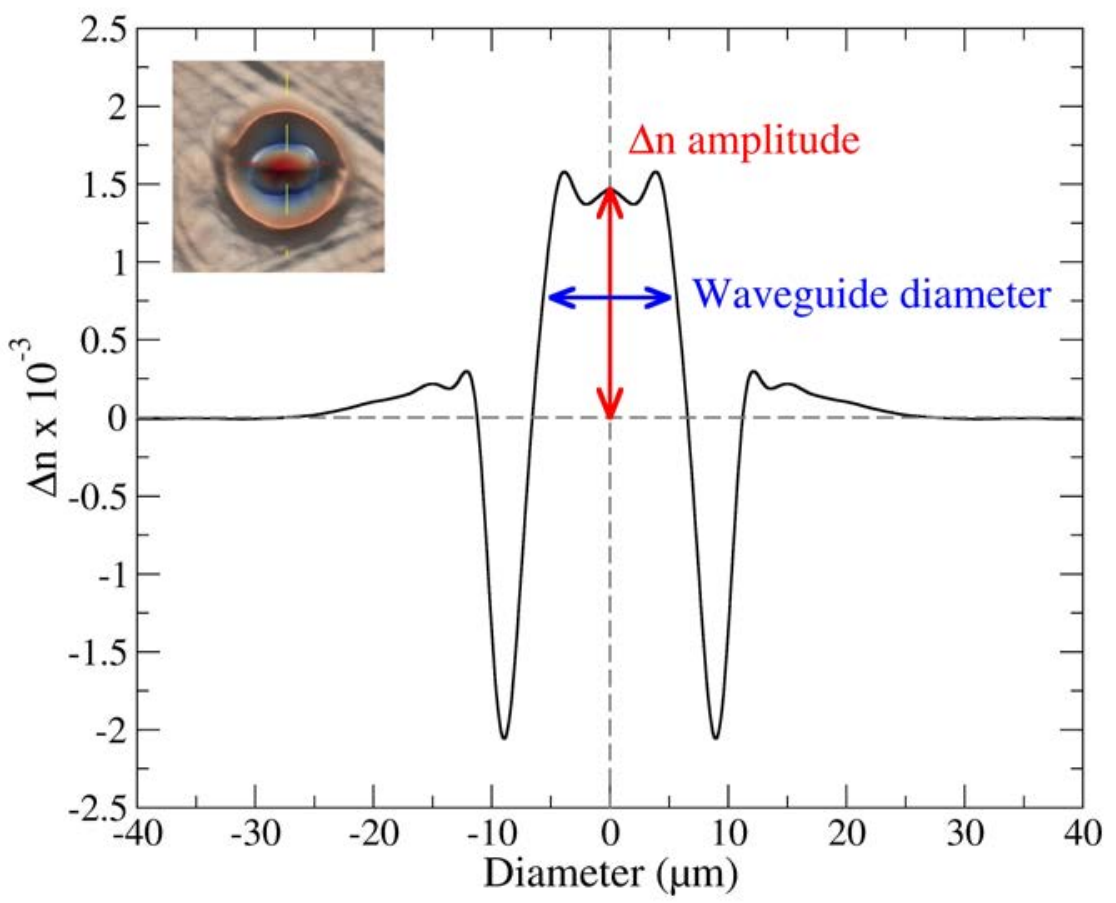

(b)
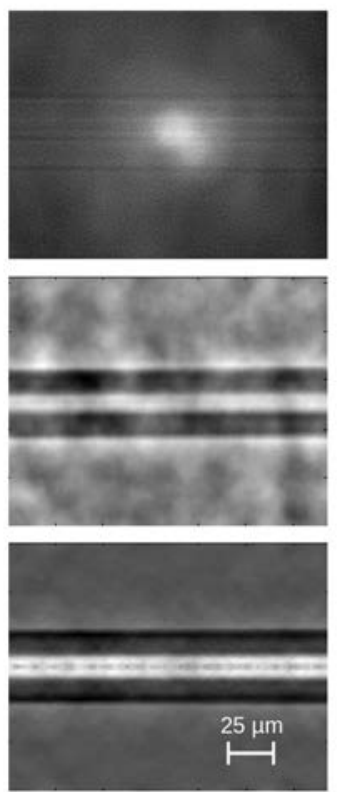

Figure 2: (a) $\Delta$ n type profile obtained by helical writing by use of femtosecond laser beam. The onset represents the $3 \mathrm{D}$ transverse $\Delta \mathrm{n}$ profile of the helical writing. The following specific parameters were applied in the present case: $v_{z}=1000 \mu \mathrm{m} / \mathrm{s}, R=9 \mu \mathrm{m}, p=25 \mu \mathrm{m}$, and $P=50 \mathrm{~mW}$. (b) From the top: microscope photo of an inscription, image of the phase matrix, and image of the index matrix $\left(v_{z}=250 \mu \mathrm{m} / \mathrm{s}, R=9 \mu \mathrm{m}, p=25 \mu \mathrm{m}\right.$, and $\left.P=50 \mathrm{~mW}\right)$

III. Results

The profile of the $\Delta \mathrm{n}$ modification generated from a helical inscription is a function of different parameters that include the helix pitch, the z-translation velocity, the helix radius or the delivered power.

\section{III.1. Influence of the helix pitch}

The first investigated parameter is the length of the helix pitch $(p)$. The other parameters were set as follows: the z-translation velocity equal to $250 \mu \mathrm{m} / \mathrm{s}$, the helix radius of $9 \mu \mathrm{m}$, and a average power of $50 \mathrm{~mW}$. The Fig. 3 depicts the $\Delta \mathrm{n}$ profiles obtained for four different values of $p$ : $5 \mu \mathrm{m}, 25 \mu \mathrm{m}, 100 \mu \mathrm{m}$, and $200 \mu \mathrm{m}$. For $p=5 \mu \mathrm{m}$, no significant $\Delta \mathrm{n}$ modification is observed. The presence of a positive $\Delta \mathrm{n}$ surrounded by a negative ring is visible for other values of $p$. Other experiments that we have carried out, have also shown that if $p<25 \mu \mathrm{m}$, the $\Delta \mathrm{n}$ amplitude is very low and inhomogeneous. From $p=25 \mu \mathrm{m}$ up to $p=150 \mu \mathrm{m}, \Delta \mathrm{n}$ is homogeneous and its amplitude continuously decreases. Moreover, the Fig. 2(b) highlights the absence of spatial period corresponding to the pitch $(p=25 \mu \mathrm{m}$ in the represented 
example). If $p>200 \mu \mathrm{m}$, the center of the waveguide begins to exhibit a decrease of the $\Delta \mathrm{n}$ until appearances of uninscribed zones and inhomogeneities. Another point has to be emphasized: for homogeneous inscriptions, the waveguide diameter, as defined in Fig. 2(a) remains almost constant whatever the helix pitch.
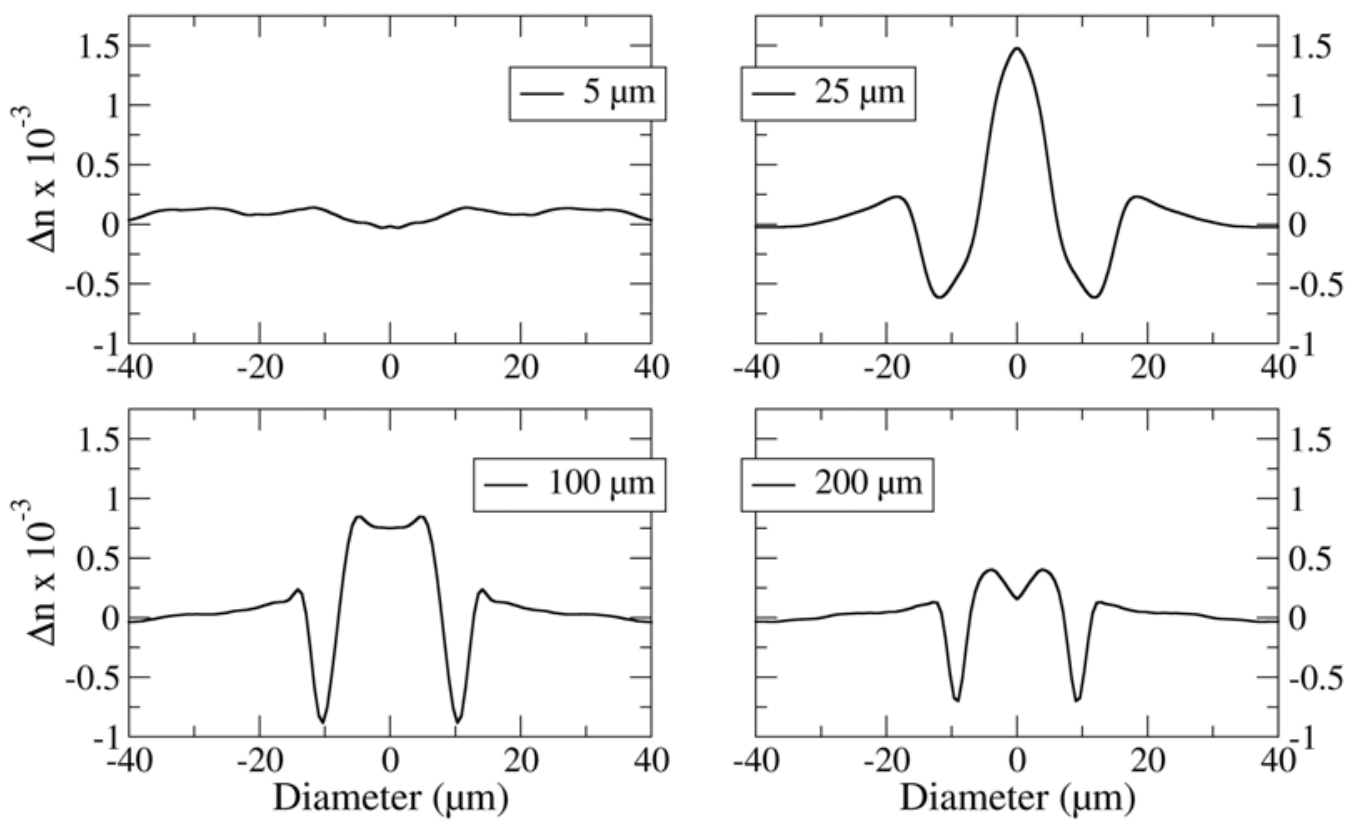

Figure 3: Examples of $\Delta \mathrm{n}$ profiles following the length of the helix pitch $(p)$. Each inscription was performed using a z-translation velocity equal to $250 \mu \mathrm{m} / \mathrm{s}$, a helix radius of $9 \mu \mathrm{m}$, and a power of $50 \mathrm{~mW}$. $\Delta \mathrm{n}$ profile for 4 values of $p$ are plotted: $p=5 ; 25 ; 100 ; 200 \mu \mathrm{m}$.

III.2. Influence of the translation speed

The second studied parameter is the z-translation velocity $v_{z}$, which is defined as follows:

$$
\left\|s_{t z}\right\|^{2}=\left\|v_{z}\right\|^{2}+\|R \cdot \omega\|^{2}
$$

where $s_{t z}$ is the scalar velocity and R. $\omega$ the rotation speed in the transverse plane.

In Fig. 4 , the $\Delta \mathrm{n}$ profile is given for a few $v_{z}$ values, between $v_{z}=50 \mu \mathrm{m} / \mathrm{s}$ up to $v_{z}=1500$ $\mu \mathrm{m} / \mathrm{s}$. The other parameters, $p, R$, and $P$ were set at $25 \mu \mathrm{m}, 12 \mu \mathrm{m}$, and $50 \mathrm{~mW}$, respectively. At first, we can see that for $v_{z}=50 \mu \mathrm{m} / \mathrm{s}$, the $\Delta \mathrm{n}$ modification is very low and no waveguide structure is discernable. For $v_{z}=250 \mu \mathrm{m} / \mathrm{s}$, a positive $\Delta \mathrm{n}$ surrounded by a negative part is observed. Next, if the z-translation velocity is increased (typically up to $1000 \mu \mathrm{m} / \mathrm{s}$ ), the amplitude of $\Delta \mathrm{n}$ is reduced while the waveguide diameter is increased. At the same time we can also mention that the homogeneity of the inscription is also better. From $v_{z}=1500 \mu \mathrm{m} / \mathrm{s}$, the trend is reversed since inhomogeneity appears. Consequently, $v_{z}$ plays a key-role since low $v_{z}$ allows high $\Delta \mathrm{n}$ amplitude to be obtained but the waveguide diameter and also its homogeneity require a higher $v_{z}$. 


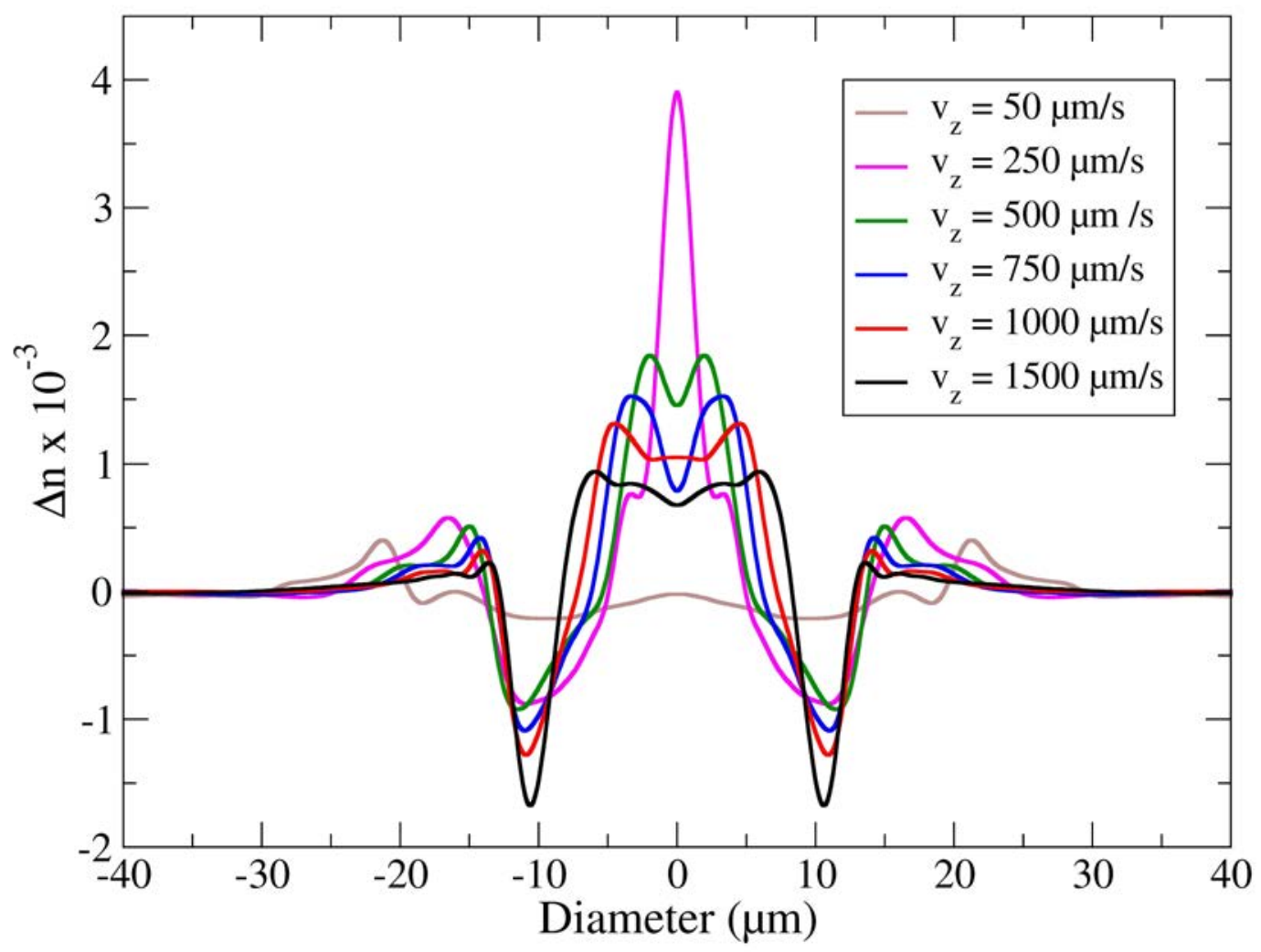

Figure 4: Examples of $\Delta \mathrm{n}$ profiles following the z-translation velocity $\left(v_{z}\right)$ obtained with a helix pitch equal to $25 \mu \mathrm{m}$ and a helix radius of $12 \mu \mathrm{m}$, and a power of $50 \mathrm{~mW}$. $\Delta \mathrm{n}$ profiles for 6 values of $v_{z}$ are plotted.

III.3. Influence of the helix radius

The third investigated parameter is the helix radius $R$. The other parameters have been fixed as follows: $p=25 \mu \mathrm{m}, P=50 \mathrm{~mW} ; v_{z}=1000 \mu \mathrm{m} / \mathrm{s}$. The $\Delta$ n profile evolution is displayed on Fig. 5 for $6 \mu \mathrm{m} \leq R \leq 14 \mu \mathrm{m}$. Actually, in these conditions we can observe that the higher is $R$, the larger is the diameter of the waveguide. For example, for $R=6 \mu \mathrm{m}$ the waveguide diameter is only $5 \mu \mathrm{m}$, while for $R=14 \mu \mathrm{m}$ it is approximately $20 \mu \mathrm{m}$. Nevertheless, at the same time a decrease of the maximum $\Delta$ n amplitude is observed from $2.2 \times 10^{-3}$ down to $1 \times 10^{-}$ ${ }^{3}$. The amplitude of the negative $\Delta \mathrm{n}$ parts surrounding the positive $\Delta \mathrm{n}$ area remains constant. Consequently, it is noticed that this parameter has a relative strong influence on the waveguide diameter in regards to the amplitude of $\Delta \mathrm{n}$. 
(a)

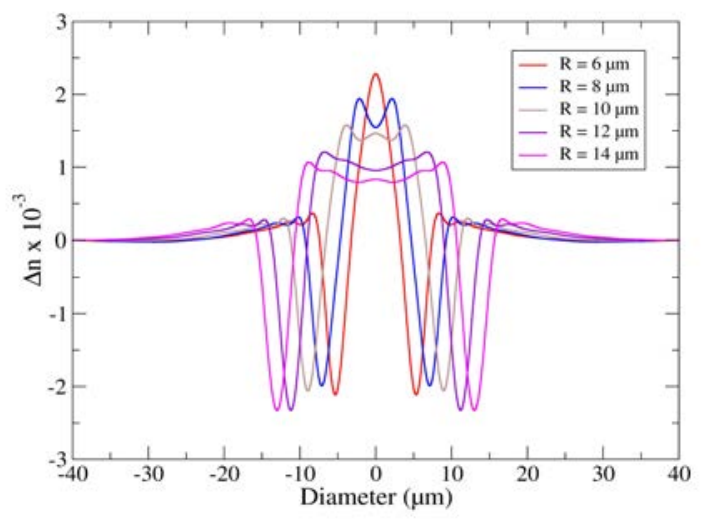

(b)

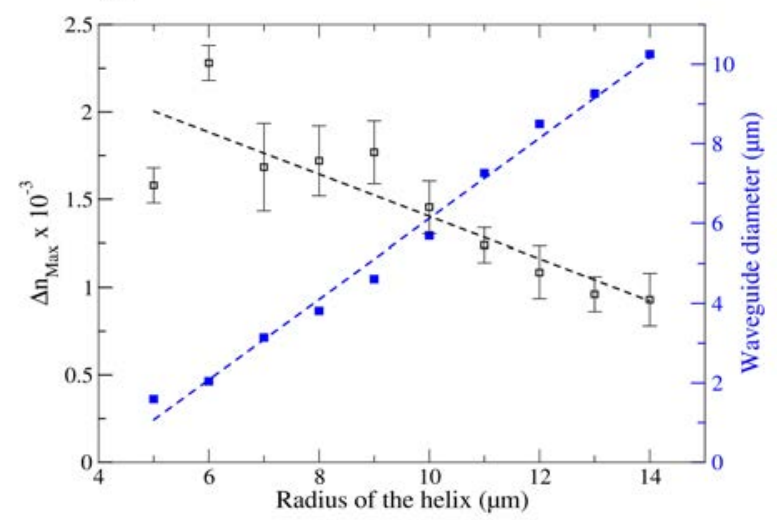

Figure 5: (a) Examples of $\Delta$ n profiles following the radius of the helix $(R)$ obtained with a helix pitch equal to $25 \mu \mathrm{m}$, a z translation velocity equal to $250 \mu \mathrm{m} / \mathrm{s}$, and a power of $50 \mathrm{~mW}$. $\Delta \mathrm{n}$ profiles for 5 values of $R$ are plotted. (b) Evolution of both $\Delta \mathrm{n}$ and the waveguide diameter following the helix radius

\section{III.4. Influence of the laser power}

The last studied parameter is the average power $P$. In Fig. 6a, the $\Delta$ n profile evolution following several $P$ between $40 \mathrm{~mW}$ and $120 \mathrm{~mW}$ is plotted. Up to $100 \mathrm{~mW}$, we clearly observe an increase of the $\Delta \mathrm{n}$ amplitude of the central peak following $P$, and from $100 \mathrm{~mW}$ up to $120 \mathrm{~mW}$, it is almost constant just above $5 \times 10^{-3}$. Concerning the negative $\Delta \mathrm{n}$ parts, a slight increase of the negative amplitude is observed. Moreover, in Fig. 6b, the $\Delta \mathrm{n}$ amplitude is displayed more accurately by using additional values of $P$. As a result, three domains are well brought out: (i) below $40 \mathrm{~mW}$, characterized by none observable $\Delta \mathrm{n}$ modification; (ii) between $40 \mathrm{~mW}$ and $90 \mathrm{~mW}$ characterized by a linear increase of the positive $\Delta \mathrm{n}$ amplitude; (iii) above $100 \mathrm{~mW}$, where a limit in term of $\Delta \mathrm{n}$ amplitude seems to be achieved $\left(\approx 5 \times 10^{-3}\right)$ and inhomogeneities also become noticeable.
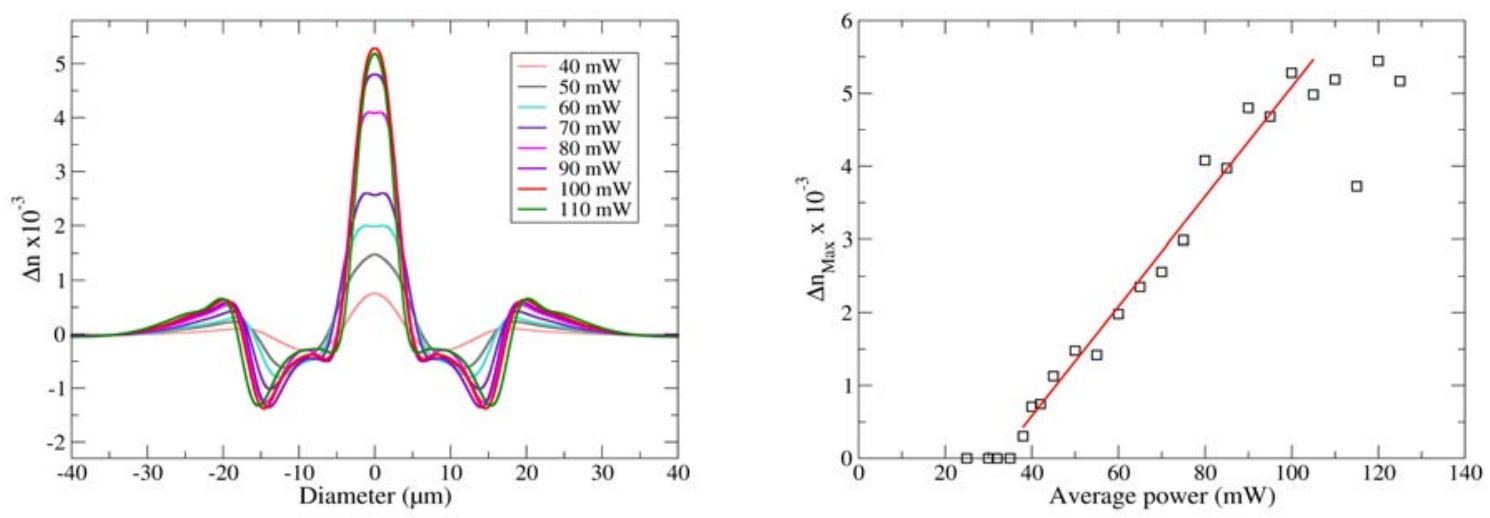

Figure 6: (a) Evolution of $\Delta$ n profiles following the power $(P)$ obtained with a helix pitch equal to $25 \mu \mathrm{m}$, a helix radius of $9 \mu \mathrm{m}$, and a z-translation velocity of $250 \mu \mathrm{m} / \mathrm{s}$. $\Delta \mathrm{n}$ profiles for 8 values of $P$ are plotted. (b) Evolution of the positive $\Delta \mathrm{n}$ amplitude as a function of the power 


\section{Discussion}

In order to understand all the results reported above, we have to consider the mechanism leading to $\Delta \mathrm{n}$. We think that in all these experiments, the thermal effect is dominant and explains the observed behaviors.

The complex morphology of $\Delta \mathrm{n}$ can be understood according to this assumption. The consequence of the local heating is a pressure wave extending from the center of the focal volume toward the outside. When the glass temperature passes over $T_{g}$, the matter can move along the same direction. Consequently, the medium is less dense in the focal volume leading to a negative $\Delta \mathrm{n}$. At the same time, we have to remember that the focal point follows a circular trajectory in the XY plan. Therefore, in all the point of this trajectory, the matter is pushed toward the center of the circle, resulting in a local densification providing that the temperature decreases below $\mathrm{T}_{\mathrm{g}}$ before the matter has enough time to relax back into its original position. Consequently, the formation of a core of positive $\Delta \mathrm{n}$ results from the combination of the dynamic of matter displacement and temperature evolution, and the motion of the sample.

This later condition explains the observed behaviour. First, let's consider the dependence of $\Delta \mathrm{n}$ with the pitch of the helix. When the value of the pitch is low, the local temperature is higher because of the high spatial and temporal overlapping of the laser pulse [25]. Therefore, the time needed for the glass temperature to decrease below $\mathrm{T}_{\mathrm{g}}$ is longer and the matter has enough time to relax back to its original location, resulting in a low $\Delta \mathrm{n}$. Once the helix pitch is sufficiently important, the heat accumulation occurs again but the transition time to reach a temperature lower than $\mathrm{T}_{\mathrm{g}}$ is shorter due to a less important overlap of the irradiated area and the matter is "quenched" in a densified state. Then, when the pitch increases further and the local temperature is lesser, the viscosity increases and the local displacement of the matter is less. Consequently, the $\Delta \mathrm{n}$ magnitude decreases when the pitch increases as observed. Also, if the pitch is too important, the inscription is not homogeneous anymore because of the nonuniformity of the heating and of the accumulation effect.

A similar explanation can be provided to interpret the dependence on the z-translation velocity. One can compare the Fig. 3(a) and $\Delta$ n corresponding to $v_{z}=50 \mu \mathrm{m} / \mathrm{s}$ in Fig. 4 . These two curves correspond to the same situation when the local temperature is very high and the matter viscosity stays low enough so that the matter local displacement can relax back to its initial state. On the other hand, when the translation speed increases, the viscosity is higher and the pressure wave displaces the matter less efficiently. Consequently, the magnitude of the resulting $\Delta \mathrm{n}$ is less and its diameter is higher.

If we consider now the dependence with the laser power, a similar interpretation can also be given. In the domain of low power (less than $40 \mathrm{~mW}$ ), any change of the index is detectable. This corresponds to a situation when the local temperature is not high enough to obtain a viscosity that allows efficient matter displacement. At high input power, $\Delta \mathrm{n}$ is not homogeneous anymore in reason of the too high temperature.

The decrease of the $\Delta \mathrm{n}$ magnitude with the radius of the helix can also be explained according to the thermal effect. In fact, as this radius is increased, the spatial overlapping of the heated zone by the laser pulse is less and once again the local temperature is less also. 
Finally, we have to mention that a heating of the sample in an oven at a temperature close to $\mathrm{T}_{\mathrm{g}}$ for a few hours erases all the $\Delta \mathrm{n}$ structures. Under such temperature condition, the viscosity is sufficiently low for the displaced matter to return to its original position and thus $\Delta \mathrm{n}$ to vanish.

It is worthy of note that a permanent $\Delta \mathrm{n}$ can also be obtained when the laser beam experiences strong self-focusing that enhances the multiphoton ionization probability [26]. However, this behavior is obtained only above a critical power that can be easily calculated [27]: under our experimental conditions, such calculation gives a value of $87 \mathrm{~mW}$ which is much higher than the threshold value observed in Fig. 4(b). Therefore, we can conclude that the influence of this mechanism does not play a significant role in our experiments.

\section{Conclusion}

In this paper, several parameters of the helical writing process have been investigated in order to evaluate their relative influence on the index profile generated in the $\mathrm{As}_{2} \mathrm{~S}_{3}$ glass. The helix radius allows controlling the waveguide diameter from typically 3 to $20 \mu \mathrm{m}$ under our experimental conditions. As for the mean power of the laser beam, it may be used to adjust the magnitude of the positive $\Delta \mathrm{n}$ of the waveguide between 0 and $5.10^{-3}$. Thus, the ability of the helical writing process to inscribe infrared waveguide in the bulk of glass with welldefined characteristics has been clearly demonstrated. This technique offers a new possibility to fabricate monomode buried waveguide in glasses notably for the infrared range with an accurate control of both the $\Delta \mathrm{n}$ magnitude and the waveguide diameter.

\section{Acknowledgements}

Dr Ophélie Caulier is very grateful to the Direction Générale de l'Armement (DGA) and the Syndicat Mixte de la Côte d'Opale (SMCO) for financial support. 


\section{References}

[1] K Davis, K. Miura, N. Sugimoto, K. Hirao, Optics Letters 1996;21(21):1729-1731

[2] S. Nolte, M. Will, J. Burghoff, and A. Tuennermann, Appl. Phys. A (2003);77:109-111

[3] R. R. Thomson, T. A. Birks, S. G. Leon-Saval, A. K. Kar, J. Bland-Hawthorn, Optics Express 2011;19(6):5698-5705

[4] J.C Ng, C. Li, P.R. Herman, L. Qian, Optics Express 2012;20(16):17894-17903

[5] M. Pospiech, M. Emons, A. Steinmann, G. Palmer, R. Osellame, N. Bellini, G. Cerullo, U. Morgner, Optics Express 2009;17(5):3555-3563

[6] C. Conseil, J.-C. Bastien, C. Boussard-Plédel, X.-H. Zhang, P. Lucas, S. Dai, J. Lucas, B. Bureau, Opt. Mater. Express 2012;2:470-1477

[7] "Chalcogenide glasses for infrared optics", Eds A. R. Hilton, S. Kemp, The McGraw Hill Companies Inc (2010)

[8] E. Bychkov, Yu. Tveryanovich, Yu. Vlasov, in: R. Fairman and B. Ushkov (Eds.) Applications of chalcogenide glasses, Semiconductors and Semimetals Series, Vol. 80, Elsevier, New York - London, 2004

[9] A. Hayashi, K. Noi, A. Sakuda, M. Tatsumisago, Nature Communications 2012;3:856

[10] Chalcogenide glasses: preparation, properties and applications”, Eds. J.L. Adam, X.H. Zhang, Woodhead Publishing 2014

[11] C. Lin, L. Calvez, B. Bureau, H. Tao, M. Allix, Z. Hao, V. Seznec, X. Zhang, X. Zhao, Phys. Chem. Chemical Phys. 2010;12(15):3780-3787

[12] B. J. Eggleton, B. Luther-Davies, and K. Richardson, Nat. Photonics 2011;5:141-148

[13] I Blonskyi, V. Kadan, O. Shpotyuk, M. Iovu, P. Korenyuk, I. Dmitruk, Applied Phys B 2011;104(4):951-956

[14] O.M. Efimov, L.B. Glebov, K.A. Richardson, E. Van Stryland, T. Cardinal, S.H. Park, M. Couzi, J.L. Brunéel, Opt. Mater. 2001;17:379-386

[15] J. F. Viens, C. Meneghini, A. Villeneuve, T.V. Galstian, E.J. Knystautas, M.A. Duguay, K.A. Richardson, T. Cardinal, J. Lightwave Technol. 1999;17:1184-1191

[16] D. Le Coq, P. Masselin, C. Przygodski, E. Bychkov, J. Non-Cryst. Solids 2009;355:1832-1835

[17] P. Masselin, D. Le Coq, A. Cuisset, E. Bychkov, Opt. Mater. Express 2012;2(12):1768-1775

[18] C. D’Amico, G. Cheng, C. Mauclair, J. Troles, L. Calvez, V. Nazabal, C. Caillaud, G. Martin, B. Arezki, E. Le Coarer, P. Kern, R. Stoian, Optics Express 2014;22(11):13091-13101

[19] D. Le Coq, P. Masselin, C. Przygodski, E. Bychkov, J. Non-Cryst. Solids 2009;355:1832-1835

[20] O. Caulier, D. Le Coq, E. Bychkov, P. Masselin, Optic Letters 2013;38(20):4212-4215

[21] A. Roberts, E. Ampem-Lassen, A. Barty, K. A. Nugent, G. W. Baxter, N. M. Dragomir, and S. T. Huntington, Optic Letters 2002;27:2061-2063

[22] A. Barty, K. A. Nugent, D. Paganin, and A. Roberts, Optic Letters 1998;23:817-819

[23] O. H. Nestor and H. N. Olsen, SIAM Review 1960;2:200-207 
[24] E. Ampem-Lassen, S. T. Huntington, N. M. Dragomir, K. A. Nugent A. Roberts, Optics Express $2005 ; 13: 3277-3282$

[25] S. Eaton, H. Zhang, P. Herman, F. Yoshino, L. Shah, J. Bovatsek, A. Arai, Optics Express 2005; $13: 4708-4716$

[26] P. Masselin, D. Le Coq, E. Bychkov, E. Lépine, C. Lin, L. Calvez, Proc. SPIE 2011;7993:79931B

[27] J. Marburger, Progress in Quantum Electronics 1975;4:35-110 